\title{
A BMP7 variant inhibits the tumorigenic potential of glioblastoma stem-like cells
}

\author{
CM Tate ${ }^{1,7}$, R Pallini ${ }^{2,7}$, L Ricci-Vitiani ${ }^{3}$, M Dowless ${ }^{1}$, T Shiyanova ${ }^{4}, G Q D^{\prime}$ Alessandris $^{2}$, L Morgante ${ }^{5}$, S Giannett ${ }^{5}$, LM Larocca ${ }^{6}$, \\ S di Martino ${ }^{3}$, SW Rowlinson ${ }^{4}$, R De Maria ${ }^{3}$ and L Stancato*,1
}

Glioblastoma multiforme (GBM) is among the most aggressive tumor types and is essentially an incurable malignancy characterized by resistance to chemo-, radio-, and immunotherapy. GBM is maintained by a hierarchical cell organization that includes stem-like, precursor, and differentiated cells. Recurrence and maintenance of the tumor is attributed to a small population of undifferentiated tumor-initiating cells, defined as glioblastoma stem-like cells (GSLCs). This cellular hierarchy offers a potential treatment to induce differentiation of GSLCs away from tumor initiation to a more benign phenotype or to a cell type more amenable to standard therapies. Bone morphogenetic proteins (BMPs), members of the TGF- $\beta$ superfamily, have numerous biological activities including control of growth and differentiation. In vitro, a BMP7 variant (BMP7v) decreased primary human GSLC proliferation, endothelial cord formation, and stem cell marker expression while enhancing neuronal and astrocyte differentiation marker expression. In subcutaneous and orthotopic GSLC xenografts, which closely reproduce the human disease, BMP7v decreased tumor growth and stem cell marker expression, while enhancing astrocyte and neuronal differentiation compared with control mice. In addition, BMP7v reduced brain invasion, angiogenesis, and associated mortality in the orthotopic model. Inducing differentiation of GSLCs and inhibiting angiogenesis with BMP7v provides a potentially powerful and novel approach to the treatment of GBM.

Cell Death and Differentiation (2012) 19, 1644-1654; doi:10.1038/cdd.2012.44; published online 27 April 2012

The most common and biologically aggressive malignant glioma, glioblastoma multiforme (GBM), is characterized by advanced features of malignancy including vascular proliferation and necrosis. ${ }^{1}$ GBM may develop de novo as a primary malignancy (primary GBM) or as the result of malignant progression from a lower grade glioma (secondary GBM). Despite aggressive treatment regimens, GBM ultimately recurs, ${ }^{2}$ and the median survival of patients has not improved significantly over the past decades with death typically occurring within 12 months of diagnosis. ${ }^{1}$ The poor prognosis associated with GBM has stimulated searches for novel and more specific therapeutic approaches.

Reasons for poor GBM prognosis include a highly infiltrative nature, extreme resistance to conventional therapy, and an inherent complexity and heterogeneity of the tumor. ${ }^{3}$ One hypothesis is that GBM is comprised of mixed populations of cells at various stages of differentiation, only a fraction of which can perpetuate the tumor. ${ }^{4}$ These so-called tumorinitiating cells or cancer stem cells (CSC) are hereby referred to as glioblastoma stem-like cells (GSLCs) owing to characteristics similar to those of normal adult stem cells, including self-renewal capability, multi-lineage potential, and maintained proliferation. ${ }^{5,6}$ It is unclear whether GSLCs arise from normal neural stem cells or from mature cells that have acquired selfrenewal ability. Importantly, GSLCs have key carcinogenesis traits including enhanced proliferative potential, angiogenesis, invasion, and modulating immune responses, while ultimately contributing to therapeutic resistance and tumor recurrence..$^{6,7}$

Similar to most solid tumors, GBMs require active angiogenesis for growth and survival. ${ }^{6}$ Interestingly, GSLCs display greater angiogenic potential in vitro and in vivo compared with non-stem-like tumor cells, which is likely related to elevated expression of proangiogenic factors, including vascular endothelial growth factor (VEGF) ${ }^{8}$ and direct contribution to the tumor vasculature through endothelial differentiation. ${ }^{9,10}$ This has led to the proposal of targeting GSLCs within the bulk tumor by inducing their differentiation into cells lacking stem cell-like properties, or to eradicate GSLCs by inhibiting the signaling pathway(s) responsible for self-renewal. Alternatively, targeting the newly formed vasculature in GBM and/or blocking endothelial differentiation of GSLCs represent a potential therapeutic strategy.

\footnotetext{
${ }^{1}$ Cancer Biology and Patient Tailoring, Oncology Research, Eli Lilly and Company, Indianapolis, IN, USA; ${ }^{2}$ Institute of Neurosurgery, Università Cattolica del Sacro Cuore, Rome, Italy; ${ }^{3}$ Department of Hematology, Oncology and Molecular Medicine, Istituto Superiore di Sanita, Rome, Italy; ${ }^{4}$ Department of Biotherapeutic Discovery Research, Eli Lilly and Company, Indianapolis, IN, USA; ${ }^{5}$ nstitute of Human Anatomy, Università Cattolica del Sacro Cuore, Rome, Italy and ${ }^{6}$ Institute of Pathology, Università Cattolica del Sacro Cuore, Rome, Italy

${ }^{*}$ Corresponding author: L Stancato, Eli Lilly and Company, Lilly Corporate Center, MC/98C/03 Room-3332, Indianapolis, IN 46285, USA. Tel: +1 317 655 6910; Fax: +1 317276 1414; E-mail: I.stancato @ lilly.com

${ }^{7}$ These authors contributed equally to this work.

Keywords: glioblastoma; cancer stem cells; bone morphogenetic protein

Abbreviations: GBM, glioblastoma multiforme; GSLC, glioblastoma stem-like cell; BMP, bone morphogenetic protein; CSC, cancer stem cell; VEGF, vascular endothelial growth factor; Sox2, SRY (sex-determining region Y)-box 2; Olig2, oligodendrocyte transcription factor 2; GFAP, glial fibrillary acidic protein; EGF, epidermal growth factor; bFGF, basic fibroblast growth factor; PARP, poly (ADP-ribose) polymerase; GFP, green fluorescence protein; FVIII, Factor VIII

Received 14.11.11; revised 22.2.12; accepted 19.3.12; Edited by P Mehlen; published online 27.4.12
} 
Bone morphogenetic proteins (BMPs), members of the transforming growth factor- $\beta$ (TGF- $\beta$ ) superfamily, are activated during embryogenesis and are required for differentiation of neuronal stem cells and subsequent neural development. ${ }^{11}$ BMPs are expressed throughout the central nervous system regions during development and may regulate additional early neural cellular processes and participate in neuronal maturation. ${ }^{12}$ BMPs bind to type I and type II receptor homodimers and activate the Smad signaling pathway through phosphorylation of receptor Smads1, 5, and 8, which then associate with Smad4 to form a heteromeric complex that translocates to the nucleus and stimulates target gene expression. ${ }^{13}$

Given the involvement of GSLCs in GBM biology and the regulatory effect of BMPs on neural stem cells and their progenitors, we evaluated the effects of a BMP7 variant (BMP7v) on proliferation, differentiation, angiogenesis, and in vivo tumorigenicity of GSLCs isolated from surgical specimens of primary GBM. BMP7v decreased proliferation of GSLCs, induced their differentiation into neuronal- and astrocyte-like lineages, and inhibited angiogenic endothelial cord formation. In vivo analysis of subcutaneous or orthotopically implanted GSLC tumor models reflect in vitro results, namely BMP7v significantly reduced tumor cell growth, increased the amount of neuronal- and astrocyte-like cells, and decreased angiogenesis. In addition, BMP7v decreased brain invasion of GSLCs while increasing survival. Current cancer therapeutics target and kill differentiated tumor cells that comprise the bulk of the tumor, whereas likely failing to affect the rare cancer stem-like cell population. Our data indicate that BMP7v therapy, directed against GSLCs and angiogenesis, represents a potentially powerful therapeutic option for GBM that may improve upon the poor outcome of conventional treatments.

\section{Results}

BMP7v reduced GSLC proliferation. Increasing evidence strongly supports a key role for GSLCs in brain carcinogenesis, necessitating the development of model systems more representative of GSLCs to identify potential novel therapies. GSLC lines, established from surgical specimens of adult GBM patients, ${ }^{3,14}$ grow as suspension and semi-adherent neurospheres (Supplementary Figure S1A, Supplementary Table S1) and proliferate in serum-free media supplemented with epidermal growth factor (EGF) and basic fibroblast growth factor (FGF) ${ }^{14,15}$ There are a number of markers available to assess stem cell characteristics and astrocyte or neuronal differentiation of GSLCs. SRY (sex-determining region $Y$ )-box 2, Sox2, and Nanog are transcription factors essential for stem cell self-renewal capability and tumorigenicity. ${ }^{16,17}$ Sox2 is a marker for undifferentiated and proliferating cells, and its expression is upregulated in highly anaplastic areas of glioblastoma. ${ }^{16}$ Oligodendrocyte transcription factor 2, Olig2, is uniquely expressed in neural stem or progenitor cells and is differentially expressed in GSLCs relative to non-stem-like tumor cells. ${ }^{18}$ Nestin is an intermediate filament protein expressed in the developing mammalian brain by neuroepithelial stem and progenitor cells. ${ }^{19}$ During the maturation of the neuronal stem cells into neurons and astrocytes, the expression of Nestin is replaced by that of neuronal intermediate filaments and glial fibrillary acidic protein (GFAP). ${ }^{20} \mathrm{U}-87-\mathrm{MG}$, a commonly studied glioblastoma cell line, was used to compare protein expression of stem cell markers and GFAP to three GSLC lines (GSLC1, 28, and 61). GSLCs maintained their stem cell-like properties as evidenced by robust expression of Sox2, Olig2, Nestin, and Nanog but failed to express GFAP (Supplementary Figure S1B). In contrast, U-87-MG cells, grown adherently in $10 \%$ serum or grown as semi-adherent neurospheres under GSLC conditions, failed to express the stem cell markers Sox2, Olig2, and Nestin, had markedly decreased expression of Nanog compared with the GSLCs, and expressed the astrocyte marker GFAP (Supplementary Figure S1B). Consequently, U-87-MG cells represent a more mature, differentiated cell population compared with GSLCs.

Despite dividing slowly, GSLCs are essential for sustaining the growth of the tumor. ${ }^{21}$ Because different proliferative potentials (doubling times $40-80 \mathrm{~h}$ ) were observed within the GSLCs isolated from patients compared with U-87-MG cells grown in $10 \%$ or $1 \%$ serum (doubling time $\sim 23$ and $\sim 48 \mathrm{~h}$, respectively), cell lines were treated with BMP7v for at least three cell doublings. BMP7v was compared with wild-type BMP7 for its ability to affect GSLC1 proliferation and led to enhanced reduction in GSLC1 number compared with wildtype BMP7 and was used in all future experiments (Supplementary Figure S1C). BMP7v caused a marked decrease ( $\sim 3-5$ fold increase in doubling time) in GSLC number compared with phosphate-buffered saline (PBS) controls (Figure 1a). In contrast, BMP7v did not affect cell proliferation of U-87-MG cells cultured in $10 \%, 1 \%$, or in serum-free growth conditions, or a variety of tumor cell lines representing a range of histologies (lung: H-1975, A-549, LXFA-649; ovarian: A-2780, SK-OV-3; melanoma: A-375; colon: HCT-116; breast: MDA-MB-231; renal: 786-0; and prostate: PC-3) (Supplementary Figure S1D). However, BMP7v induced canonical BMP signaling within 15 minutes in U-87-MG and GSLCs, as evidenced by phosphorylation of Smad transcription factors (Smad1, 5, and 8), indicating expression of functional BMP7 receptors (Figure 1b).

Given the dramatic decrease in GSLC proliferation observed with BMP7v, we analyzed expression of the nuclear antigen Ki67, a proliferation marker expressed during the active phases of the cell cycle, and cleaved poly (ADP-ribose) polymerase (PARP), a marker for apoptosis. Consistent with cell proliferation data, BMP7v did not alter Ki67 protein expression in U-87-MG cells but strongly reduced Ki67 expression in GSLCs (Figure 1c). This reduction in GSLC proliferation was not due to an increase in apoptosis as BMP7v did not alter PARP cleavage (Figure 1c) or increase TUNEL staining (data not shown). Consistent with the decrease in GSLC proliferation, BMP7v significantly decreased $(P<0.05)$ expression of the mitotic marker phospho-histone $\mathrm{H} 3$ both by high-content imaging and western blot analysis (Figure 1d). Cell cycle analysis revealed a trend towards an increase in cells in G1 and a decrease in cells in S and G2/M phases in GSLCs treated with BMP7v, although these differences were not statistically significant (data not shown). 

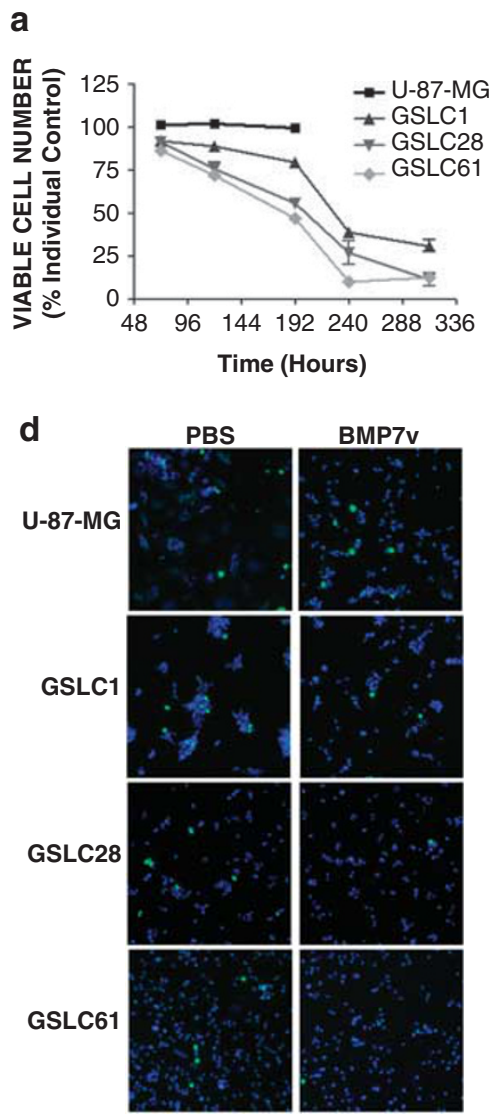

b



C
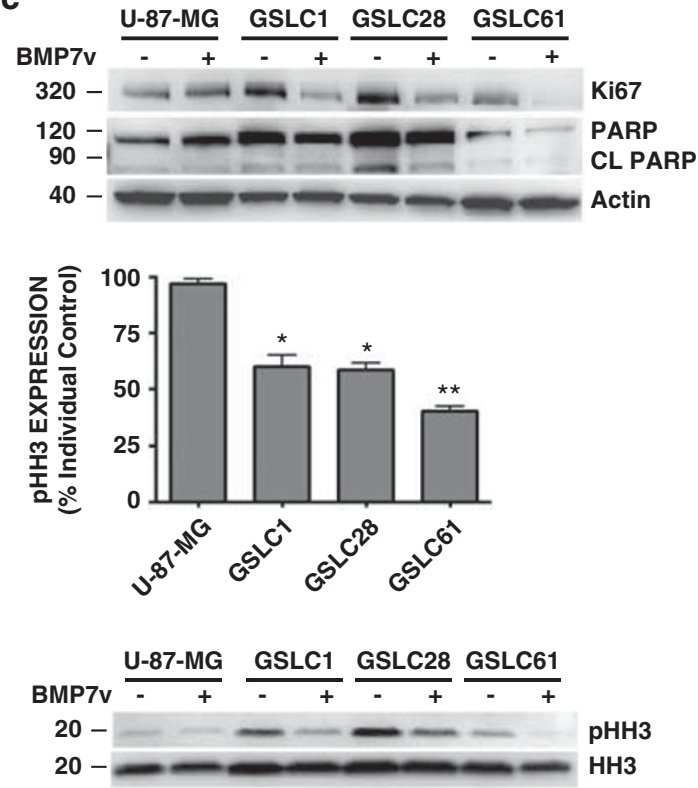

Figure 1 BMP7v reduced GSLC proliferation. (a) U-87-MG cells and GSLCs isolated from three separate patients were treated with $100 \mathrm{ng} / \mathrm{ml} \mathrm{BMP7v}$ and analyzed over a time course of at least three cell doublings and compared with their respective PBS-treated controls. Results represent mean plus S.E.M. for three independent experiments. (b and c) Whole-cell protein extracts were isolated following $15 \mathrm{~min}$ (b) or 7 day (c) PBS $(-)$ or $100 \mathrm{ng} / \mathrm{ml} \mathrm{BMP7v}(+)$ treatment and subjected to western blot analysis using antiserum directed against Smad1,5,8-phosphorylation (pSMAD1,5,8), Ki67, PARP, cleaved PARP (CL PARP), and $\beta$-actin as a loading control. Results shown are representative of three independent experiments. (d) Individual cells were plated for high-content analysis following 7 days of PBS or $100 \mathrm{ng} / \mathrm{ml} \mathrm{BMP7v}$ treatment. Cells were detected using Hoescht dye (blue) to stain the nuclei, and phospho-histone $\mathrm{H} 3(\mathrm{pHH})$ expression (green) was compared between PBS and BMP7v-treated cells using the percentage of cells expressing a minimum total amount of pHH3 for each cell line (X10 magnification). Results represent mean plus S.E.M. for three independent high-content experiments. Asterisks denote statistically significant (Student $t$-test; ${ }^{*} P<0.05$; ${ }^{* *} P<0.01$ ) differences compared with PBS controls. Whole-cell protein extracts were isolated following 7 days of PBS $(-)$ or $100 \mathrm{ng} / \mathrm{ml} \mathrm{BMP7v}(+)$ treatment from the indicated cell lines and subjected to western blot analysis using antiserum directed against pHH3 and total histone $\mathrm{H} 3(\mathrm{HH} 3)$ as a loading control. Results shown are representative of three independent experiments

BMP7v induced differentiation of GSLCs. Given the pivotal role that BMPs have in neural stem cell differentiation and the multipotency of GSLCs,, ,10,22 BMP7v was analyzed for its ability to induce GSLC differentiation through morphological and protein marker analysis. Upon serum differentiation, GSLCs become elongated and grow adherently ${ }^{15}$; therefore, morphology is likely an acceptable endpoint to determine treatment-dependent phenotypic changes. BMP7v treatment of GSLC1 and GSLC61 resulted in a semi-adherent morphology compared with unattached, suspension neurospheres observed with PBS controls in tissue culture-treated flasks (Figure 2a). In contrast, GSLC28 did not become adherent upon BMP7v treatment in tissue culture-treated flasks but displayed markedly reduced neurosphere size compared with PBS controls (Figure 2a). An attached morphology without the presence of neurospheres was observed when GSLC1, 28, and 61 were plated on laminin-coated flasks and treated with BMP7v compared with PBS controls (Supplementary Figure S2). To analyze differentiation, protein expression of the astrocyte marker GFAP and neuronal marker $\beta$ III-tubulin (Tuj1-like), a structural protein expressed in neural cells and neural precursors were assessed. Following BMP7v treatment, GSLCs exhibited reduced expression of the stem cell markers Sox2, Nestin, Olig2, and Nanog and increased expression of GFAP and $\beta$ III-tubulin. Protein expression by western blot is representative of the whole-cell population and does not reflect signal heterogeneity across cellular subpopulations. In order to assess changes in subpopulations following BMP7v treatment, high-content analysis of cell cycle in conjunction with differentiation marker expression was used as previously described. ${ }^{15}$ The data are displayed as heatmaps, and cell cycle position was determined by simultaneously monitoring nuclear DNA content, nuclear area, average DNA content, and DNA variation as previously described. ${ }^{23}$ Each horizontal line represents a single cell, and the cells were sorted vertically within each cluster using unsupervised $K$-means clustering based on total DNA content, with the 
a

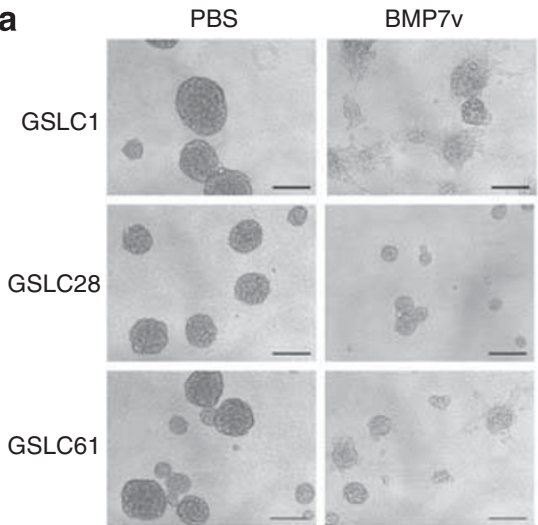

C

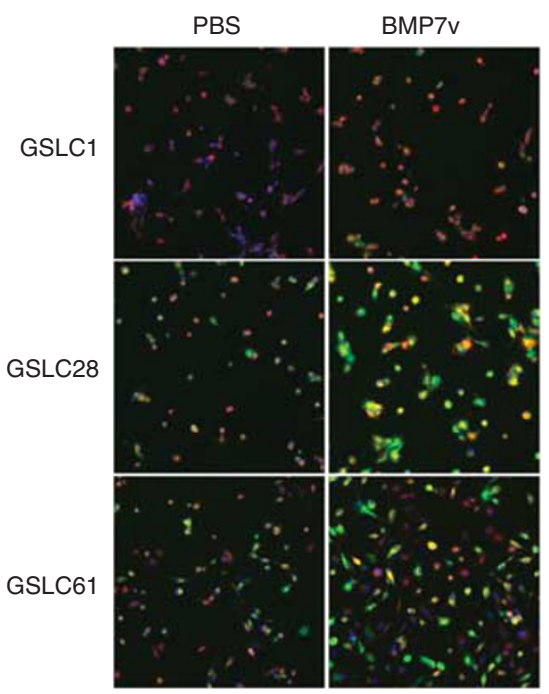

b

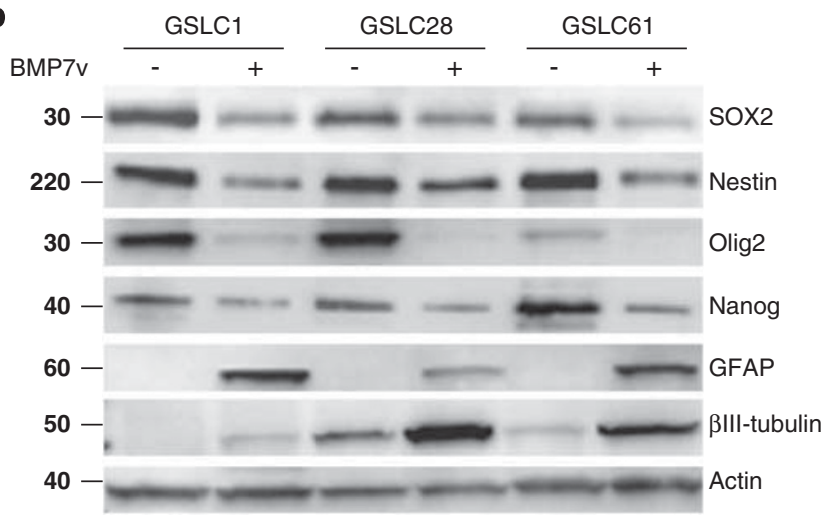

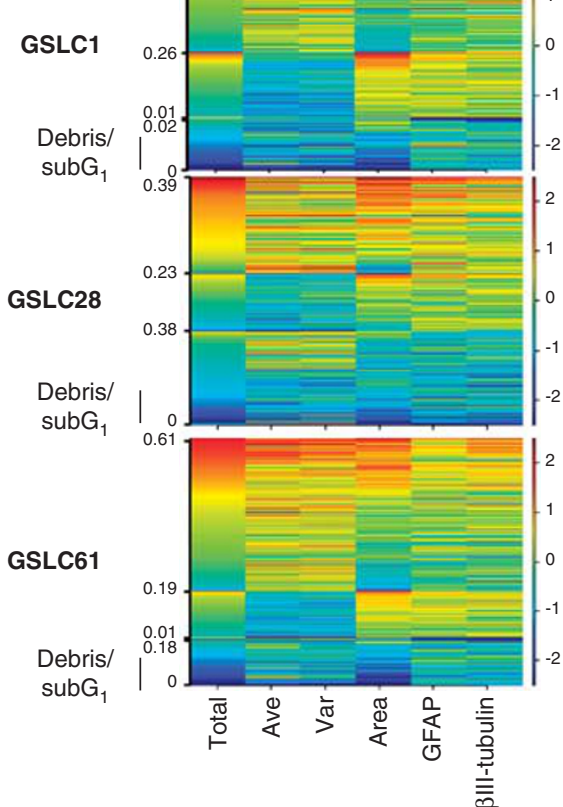

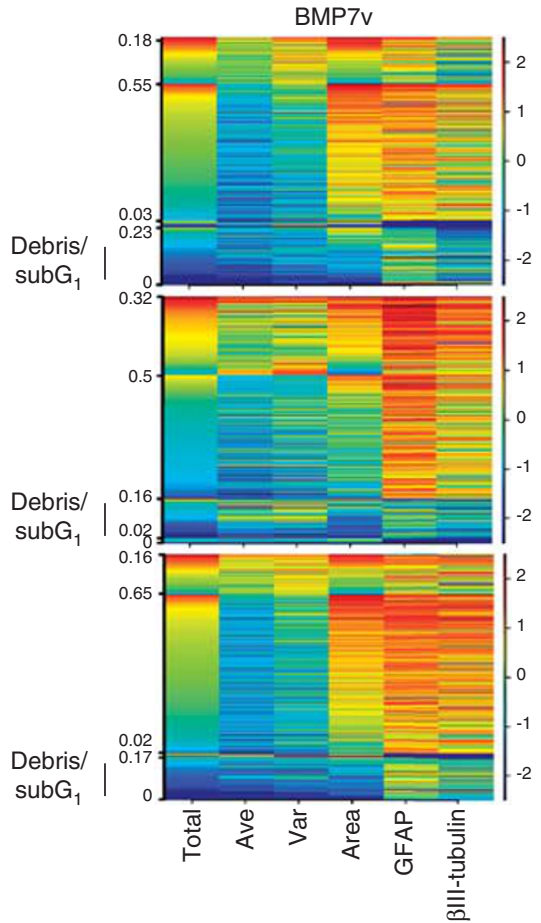

Figure 2 BMP7v-induced differentiation of GSLCs. (a) Light micrographs represent cell morphology (X10 magnification, scale bars are $100 \mu \mathrm{m})$ following 7 days of PBS or $100 \mathrm{ng} / \mathrm{ml} \mathrm{BMP7v}$ treatment. (b) Whole cell protein extracts were isolated following 7 days of PBS $(-)$ or $100 \mathrm{ng} / \mathrm{ml} \mathrm{BMP7v}(+)$ treatment and subjected to western blot analysis using antiserum directed against Sox2, Nestin, Olig2, Nanog, GFAP, $\beta$ III-tubulin, and $\beta$-actin as a loading control. (a and b) Results shown are representative of three independent experiments. (c) Individual cells were plated for high-content analysis following 7 days of PBS or $100 \mathrm{ng} / \mathrm{ml} \mathrm{BMP7v}$ treatment. Cells were detected using Hoescht dye (blue) to stain the nuclei, GFAP (red), and $\beta$ III-tubulin (green). To determine relative levels of expression, staining intensities were compared with PBS controls and represented as heatmaps that clustered the data from individual cells and sorted each cluster based on the total DNA intensity of the nucleus. The numbers on the left side of each heatmap denote the fraction of cells in each cluster. The parameters measured are listed below each column: total DNA intensity (Total), average DNA intensity (Ave), variation of DNA intensity (Var), nuclear area (Area), total GFAP (GFAP), and total $\beta$ III-tubulin ( $\beta$ III-tubulin). Images and heatmaps shown are representative of three independent experiments

individual cell variables displayed horizontally across the heatmaps. The data are plotted on a color scale where red denotes an increase above the mean of the control, and blue indicates a decrease below the mean of the control. In agreement with cell cycle flow cytometry data, BMP7v increased the G1 subpopulation as evidenced by a larger subpopulation that displayed reduced average DNA content and DNA variation (Figure 2c). Similar to western blot analysis, BMP7v increased GFAP and $\beta$ III-tubulin expression (Figure 2c) but their expression was not mutually exclusive, indicating that GSLCs co-expressed astrocyte and neuronal markers within the same cell. This further supports previous reports of abnormal differentiation properties of GSLCs. ${ }^{15,24}$ Consequently, BMP7v resulted in a more mature phenotype of GSLCs akin to differentiation.

Because GSLCs derived from patients show different proliferative potential and tumor-initiating ability, reflecting the inherent heterogeneity of human GBMs, ${ }^{25}$ we analyzed the effects of BMP7v on the proliferation and differentiation of eight additional patient-derived GSLC lines. Consistent with 
observations in cell lines GSLC1, 28, and 61, BMP7v treatment reduced cell number and $\mathrm{Ki} 67$ protein level in the additional GSLC lines without altering the level of cleaved PARP (Supplementary Figure S3). BMP7v treatment also decreased protein expression of the stem cell markers Sox2, Nestin, Olig2, and Nanog in all GSLC lines, whereas the majority of cell lines displayed increased GFAP and $\beta \mathrm{III}$ tubulin protein expression (Supplementary Figure S3). Taken together, these in vitro results indicate that BMP7v reduced GSLC proliferation and induced differentiation of GSLCs into neuronal- and astrocyte-like cells.

\section{BMP7v reduced GSLC-induced endothelial cord forma-} tion. GBM is highly vascularized, and GSLCs have been shown to express high levels of proangiogenic factors. ${ }^{8,26}$ Because BMPs are involved in the regulation of angiogenesis during embryonic development and bone formation, ${ }^{27}$ effects on vascular endothelial cell cord formation, an in vitro surrogate measure of angiogenesis, were analyzed. GSLCs were grown in a permeable trans-well system with a coculture of endothelial colony-forming cells (ECFCs) and adipose-derived stem cells (ADSCs), and endothelial cord formation was measured by expression of the endothelial cell marker cluster of differentiation-31 (CD31). BMP7v significantly reduced cord formation induced by GSLCs $(P<0.001)$, as measured by total cord area (Figure 3$)$. BMP7v also significantly reduced endothelial cord formation induced by the eight additional GSLC lines $(P<0.05$; data not shown), suggesting a broad antiangiogenic function of BMP7v in vitro. However, BMP7v did not alter expression of the secreted proangiogenic factors VEGF, bFGF, or EGF from the GSLCs compared with PBS controls

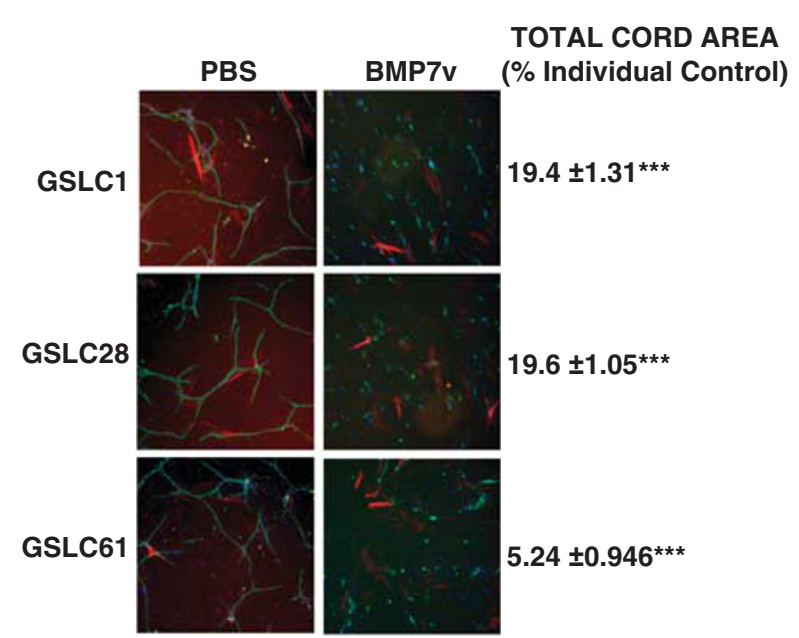

Figure 3 BMP7v inhibited GSLC-induced cord formation. GSLCs were plated into a permeable trans-well system with a co-culture of ADSCs and ECFCs in serum-free media. Following a 4-day treatment with PBS or $100 \mathrm{ng} / \mathrm{ml} \mathrm{BMP7v}$, ADSCs and ECFCs were detected using Hoescht dye (blue) to stain the nuclei, and cord formation was assessed by immunofluorescence for CD31 (green) and smooth muscle actin (red) (X5 magnification). Numbers represent mean total cord area \pm S.E.M. as a percent of the PBS control, and images shown are representative of three independent experiments. Asterisks denote statistically significant (Student $t$-test; ${ }^{* \star *} P<0.001$ ) differences compared with PBS controls
(Supplementary Figure S4). This suggests that BMP7v may alter the ability of endothelial cells to form cords.

BMP7v reduced the growth and increased differentiation of GSLC xenografts. In immunocompromised mice, human GSLCs grown under serum-free culture conditions generate tumors that reproduce the histological and molecular features of the parent neoplasm, ${ }^{14,22}$ are resistant to chemotherapy, ${ }^{3}$ and represent an ideal model to explore new modalities of treatment. A key feature of tumor xenografts generated by intracerebral injection of human GSLCs is the highly infiltrative growth pattern that closely mimics the behavior of malignant human gliomas. This infiltrative nature distinguishes orthotopic GSLC xenografts from models based on grafting of human GBM cells established with serum-containing media, like U-87-MG, which mainly display local growth resulting in circumscribed brain lesions. A stable green fluorescence protein (GFP)expressing GSLC1 line, that retains the same in vitro proliferation and differentiation response to BMP7v as the parental line, was used for in vivo analysis owing to its high propensity to invade the brain. Within a few weeks after grafting, the GSLCs typically spread from the injection site towards distant brain regions with a special tropism for the large paths of white matter, such as the corpus callosum and anterior commissure. Using this model, the effect of a single intracerebral dose $(1 \mathrm{ng})$ of BMP7v on tumor growth was analyzed. Two weeks after grafting, control mice displayed GFP-expressing tumor cells at the injection site with spreading towards the homolateral striatum and piriform cortex (Figures $4 a$ and b). By 4 weeks after grafting, the tumor had invaded the corpus callosum and anterior commissure, whereas the internal capsule, optic tract, septal nuclei, and fimbria-hippocampus were invaded by the tumor after 8 weeks (Figure 4c, left panel). A single dose of BMP7v significantly inhibited the growth and invasion of brain tumor xenografts (Figure 4c, right panel). At 2, 4, and 8 weeks after grafting, both the cranio-caudal extension and the volume of the brain invaded by the GFP-expressing GSLCs were significantly decreased (Figure $4 d$ and Table $1, P<0.05$ ). In particular, 8 weeks after grafting, the mitotic index (MI) and expression of Nestin were significantly lower $(P<0.05$ and $P<0.01$, respectively), and the expression of both the astrocyte marker GFAP and of neuronal marker $\beta$ III-tubulin were significantly higher $(P<0.001$ and $P<0.002$, respectively) in BMP7v-treated tumors than control tumors (Figures 5b and e and Table 1). BMP7v-treated tumors also showed significantly fewer cells expressing the proliferation marker Ki67 ( $P<0.05$; Figures $5 d$ and e). Interestingly, the proliferating GFP-expressing tumor cells did not express GFAP, suggesting that astrocytic differentiation correlates with growth arrest (Figure 5a).

In order to test BMP7v effects in vivo in established tumors, BMP7v was administered into immunocompromised mice bearing subcutaneous GSLC tumor xenografts. At 16 weeks after inoculation, the xenografts measured $14.8 \pm 0.6 \mathrm{~mm}$ (mean \pm S.D.; range $12-18 \mathrm{~mm}$ ) in diameter and treatment with BMP7v was initiated. BMP7v (10 ng in $100 \mu$ l of saline) was injected subcutaneously adjacent to the tumor once daily for 2 weeks ( 5 days per week; total 10 injections). Mice $(n=4)$ 
a

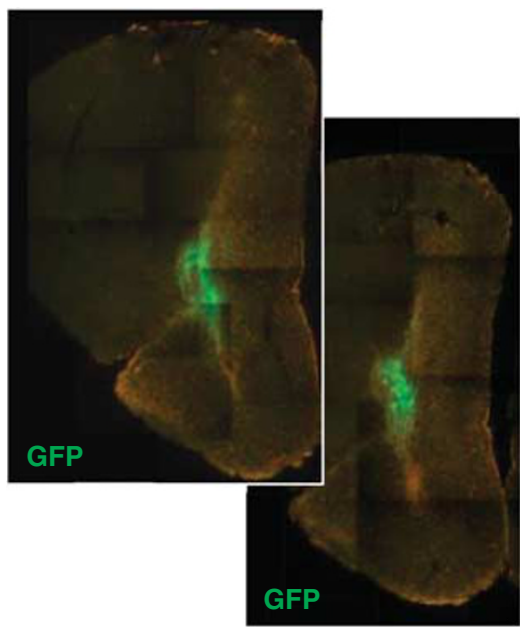

C

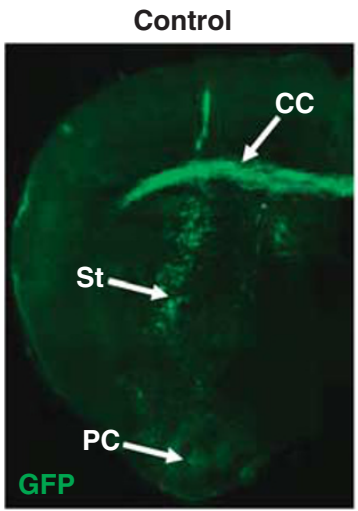

b
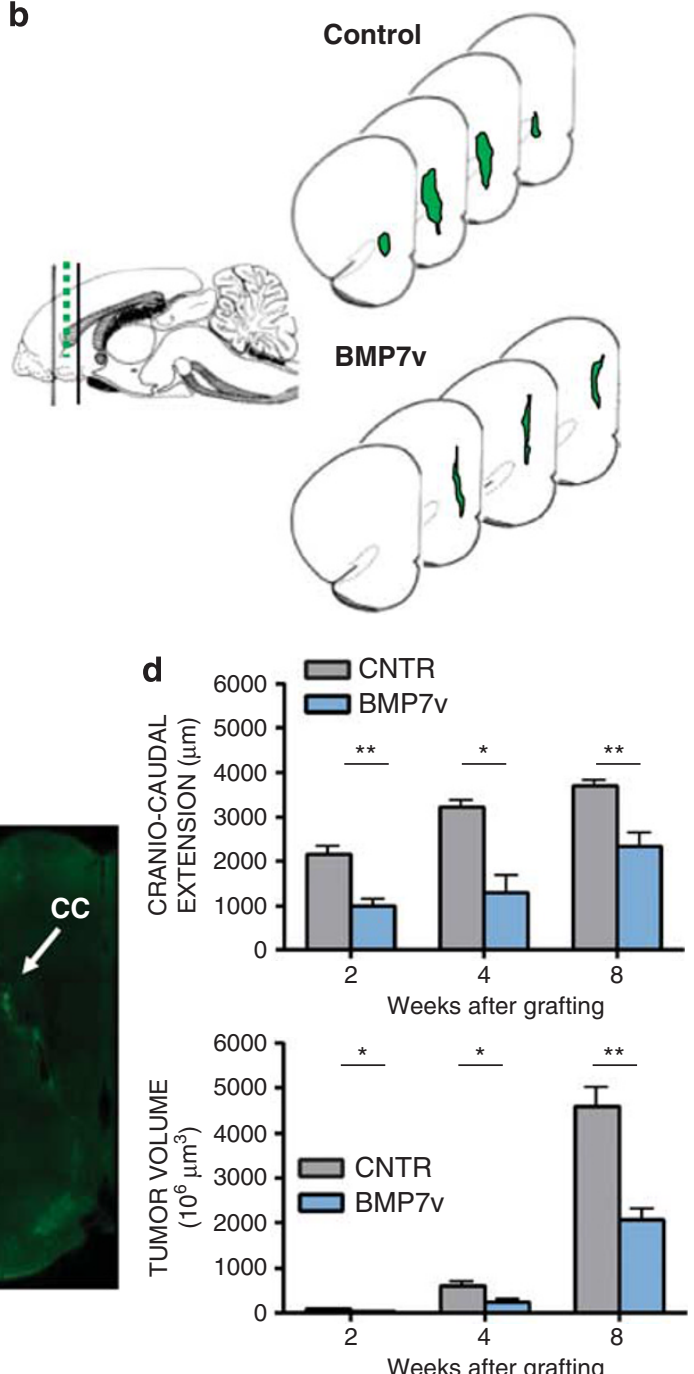

Figure 4 BMP7v reduced the proliferation and invasion of intracerebral GSLC xenografts. (a) Mice were injected intracerebrally with GFP-expressing GSLCs without BMP7v (control, CNTR) or mixed with $1 \mathrm{ng} \mathrm{BMP7v.} \mathrm{At} 2$ weeks after grafting, the tumor cells were found at the injection site, homolateral striatum, and piriform cortex (photomontage of two adjacent coronal brain sections $120 \mu \mathrm{m}$ apart). (b) Schematic drawings of the experimental paradigm in specimens with 2-week survival. (c) Coronal sections through the grafted striatum at 8 weeks after grafting (photomontages; CC, corpus callosum; St, striatum; PC, piriform cortex). (d) In BMP7v-treated mice with $2(n=3), 4(n=3)$, and $8(n=4)$ week survival, both the cranio-caudal extension and volume of the brain region invaded by the GFP-expressing GSLCs were significantly reduced (Student $t$ test; ${ }^{*} P<0.05 ;{ }^{* *} P<0.01$; results shown represent mean plus S.E.M.) compared with matched control mice (CNTR)

were maintained up to 14 days without any further treatment, except for measurement of tumor mass. Control mice $(n=4)$ were injected with an equal volume of saline. Over a 4-week observational time, which included 2 weeks of treatment and 2 weeks post treatment, the mean tumor diameter of salineinjected mice was increased by $13.3 \pm 4.3 \%$. Conversely, BMP7v-treated tumors showed a significant size reduction ( $P<0.001,47.9 \%$ decrease) compared with saline-injected controls (Supplementary Figure S5A). In BMP7v-treated tumors, there were significantly fewer mitotic figures $(P<0.001)$ compared with controls (Supplementary Figure $\mathrm{S} 5 \mathrm{~B})$. BMP7v-treated tumors also showed significant reduction of Nestin expression $(P<0.05)$ and significant increases in GFAP and $\beta$ III-tubulin expression $(P<0.01$; Supplementary Figures S5C and D), indicating an increase in differentiation. Tumor proliferation, as assessed by Ki67 staining, was also significantly lower in BMP7v-treated tumors compared with controls $(P<0.01$; Supplementary Figures S5C and D). The subcutaneous (summarized in supplementary Table S2) and orthotopic results recapitulate the in vitro observations, namely, BMP7v reduces GSLC proliferation and induces differentiation into a more mature neuronal or astrocyte-like cell type.

BMP7v reduced angiogenesis and increased survival in GSLC intracerebral xenografts. The antiangiogenic effects of BMP7v observed on in vitro endothelial cord formation and the powerful proangiogenic effect of GSLCs on tumor vascularization prompted analysis of BMP7v effects on tumor angiogenesis. ${ }^{6}$ In the striatum of BMP7v-treated intracranial xenografts, there was a significant reduction of CD31 expressing capillaries compared with controls $(P<0.01$; Figures $6 \mathrm{a}$ and $\mathrm{b}$ and Table 1$)$. Furthermore, the number of CD31expressing vascular glomeruli assessed in 

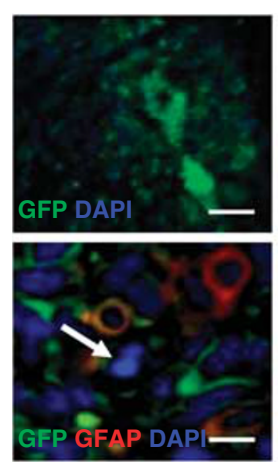

C
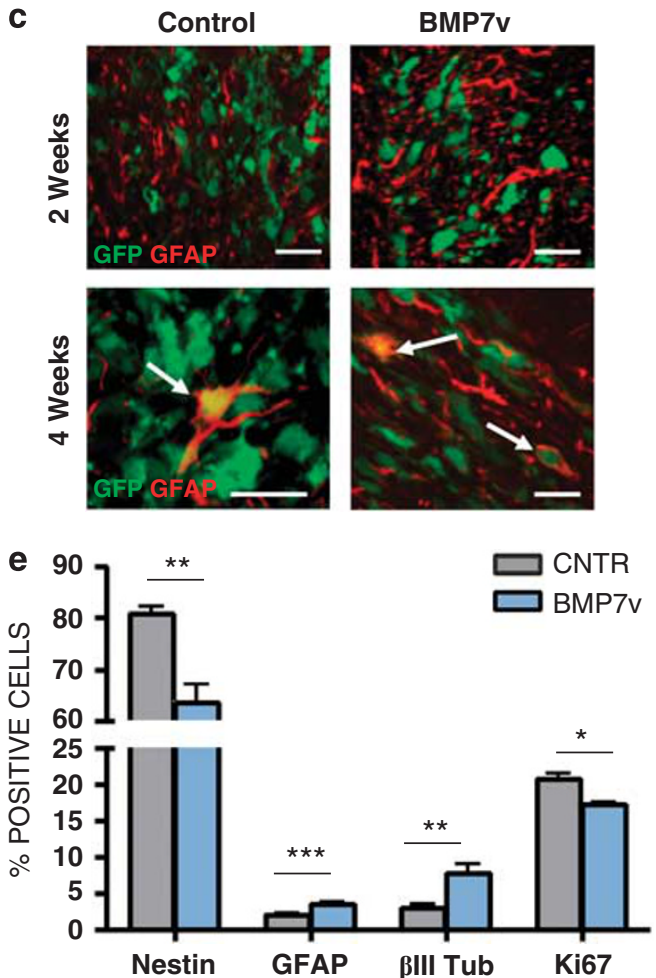

BMP7v
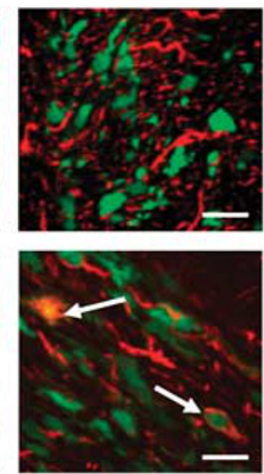

CNTR BMP7V

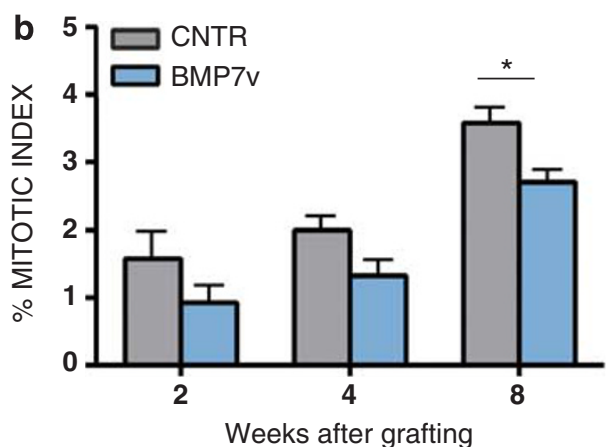

d
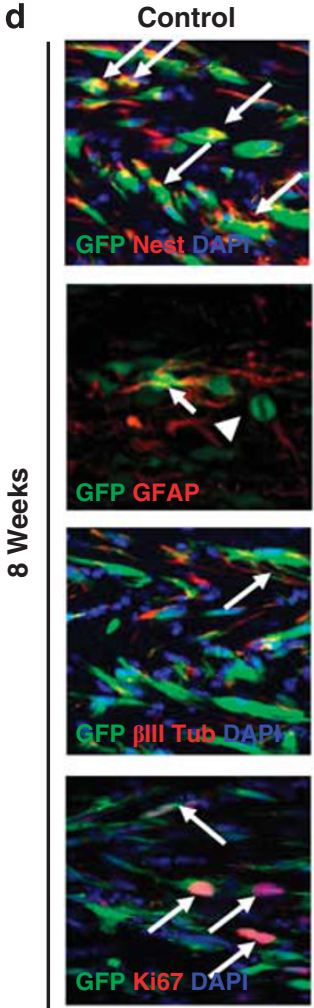
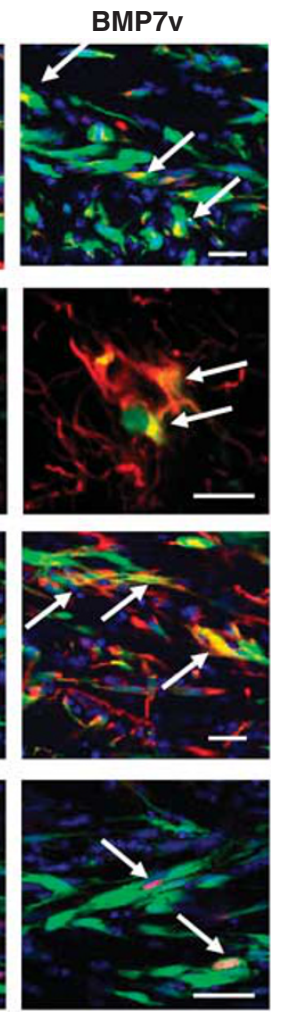

Figure 5 BMP7v reduced the proliferation and induced differentiation of intracerebral GSLC xenografts. (a) Tumor cell proliferation was assessed by counting the mitotic figures of GFP-expressing cells (upper panel; scale bars, upper left, $100 \mu \mathrm{m}$; upper right, $10 \mu \mathrm{m}$ ). The proliferating tumor cell fraction did not express GFAP (red, lower panel; arrows indicate mitotic figures; scale bars, lower left, $100 \mu \mathrm{m}$; lower right, $10 \mu \mathrm{m}$ ). (b) Eight weeks after grafting, the mitotic index (MI) was significantly lower (Student $t$-test; ${ }^{*} P<0.05$; results represent mean plus S.E.M.) in BMP7v-treated tumors (BMP7v; $n=4$ ) than in controls (CNTR; $\left.n=4\right)$. (c) Both in BMP7v-treated and in control tumors, astrocytic differentiation was absent at 2 weeks (upper panel; scale bar, $30 \mu \mathrm{m}$ ) and was first recognized 4 weeks after grafting (lower panel; scale bars, $10 \mu \mathrm{m}$ ). (d) By 8 weeks after grafting, immunofluorescence revealed that BMP7v treatment reduced the expression of Nestin (red, Nest) and Ki67 (red), whereas increasing GFAP (red) and $\beta I I I$ tubulin (red, Tub). The arrows indicate GFP-expressing tumor cells that express Nestin, GFAP, $\beta$ III tubulin, or Ki67. The arrowhead indicates a mitotic figure (scale bars, $20 \mu \mathrm{m}$ ). (e) Graph represents the expression of the stem cell marker Nestin, astrocytic marker GFAP, neuronal marker $\beta \| I I$ tubulin, and proliferation marker Ki67 in GFPexpressing tumor cells 8 weeks after grafting in either BMP7v-treated tumors $(n=4)$ or controls (CNTR, $n=4)$ (Student $t$-test; ${ }^{\star \star} P<0.001$; ${ }^{\star \star} P<0.01$, ${ }^{\star} P<0.05$; results represent mean plus S.E.M.)

sections passing through the tumor epicenter was significantly lower in BMP7v-treated xenografts compared with controls $(P<0.005$; Figures $6 \mathrm{a}$ and $\mathrm{b}$ and Table 1$)$. The xenografted brains were also immunostained using the endothelial cell markers TIE2 and Factor VIII (FVIII, von Willebrand factor) which showed a lower density of vascular structures in BMP7v-treated mice compared with controls (Supplementary Figure S6).

The decrease in tumor growth, induction of differentiation, and antiangiogenic effects of BMP7v should lead to enhanced survival following orthotopic injection of GSLCs; thus, a subset of mice were allowed to survive until the appearance of a lethargic state. Mice treated with BMP7v survived significantly longer than control mice (Figure $6 \mathrm{c} ; P<0.05$ ), and the lethargic state had its pathological counterpart with tumor invading the entire brain hemisphere and extending contra-laterally with distortion of the ventricles and midline structures (Supplementary Figure S7). Interestingly, at the late stage of tumor growth, BMP7v-treated xenografts showed a substantial increase of GFAP expression compared 
a

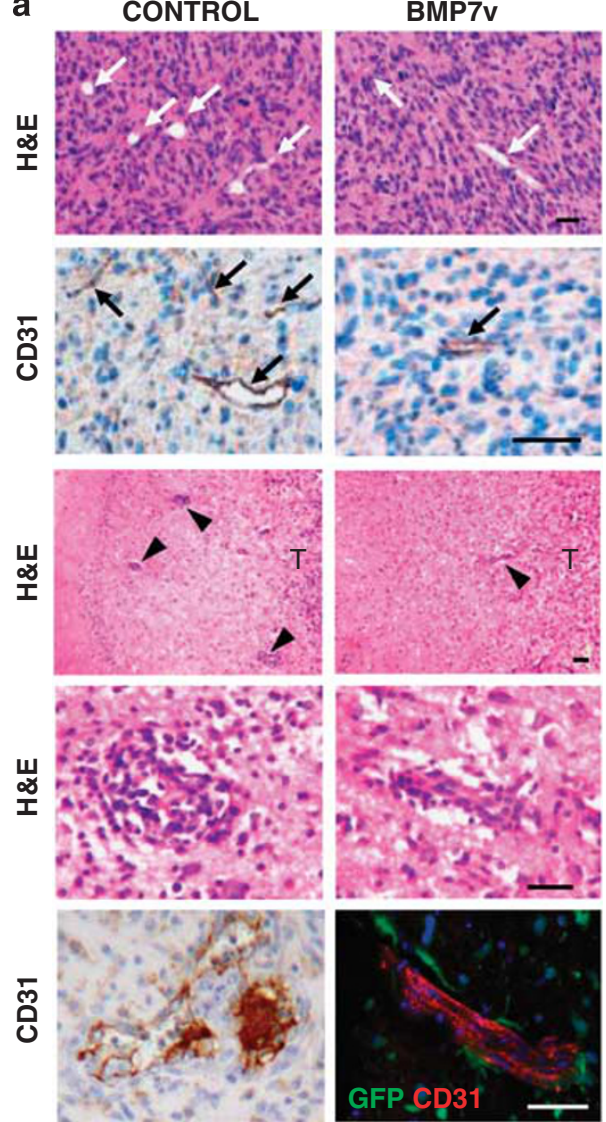

b
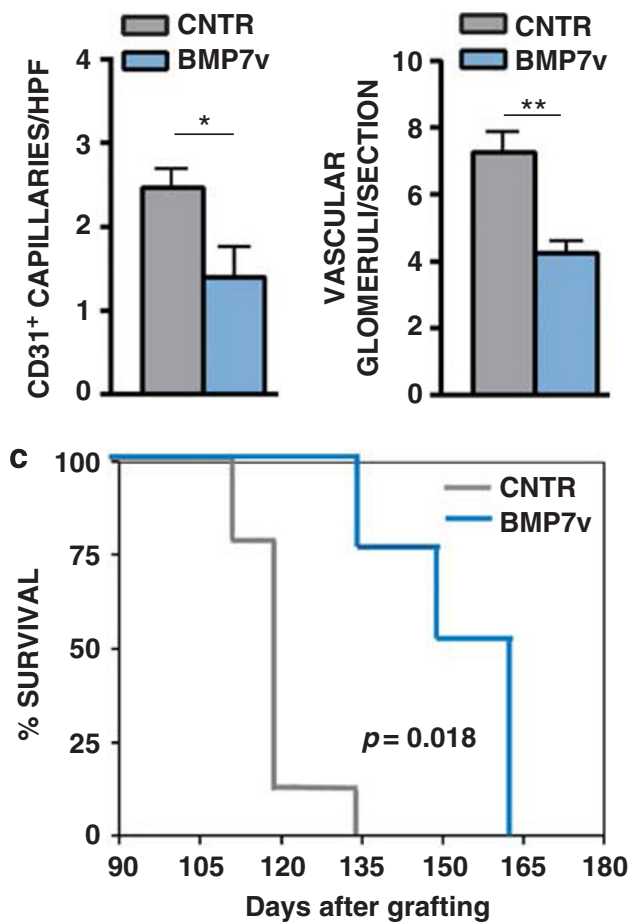

Figure 6 BMP7v reduced angiogenesis in the striatum and increased survival following intracerebral GSLC xenografts. (a) Vascular structures in the striatum of BMP7v-treated and control xenografts (H\&E; anti-CD31 immunostaining; arrows indicate tumor capillaries; arrowheads indicate vascular glomeruli; scale bars, $50 \mu \mathrm{m})$. (b) By 8 weeks after grafting, the density of CD31-positive capillaries and vascular glomeruli was significantly lower in the striatum of BMP7v-treated tumors ( $n=4)$ compared with controls $(n=4)$ (Student $t$-test; ${ }^{\star} P<0.05,{ }^{\star \star} P<0.01$, results represent mean plus S.E.M.). (c) The graph represents the survival probability curves in mice harboring brain tumor xenografts, which were either treated with $1 \mathrm{ng} \mathrm{BMP7v}(n=4)$ or untreated (CNTR, $n=4)$. There is a significant difference between the curve for BMP7v-treated and untreated (CNTR) mice (log rank test; $P=0.018$ )

Table 1. Summary of results from brain tumor xenografts

\begin{tabular}{|c|c|c|c|}
\hline Paradigm & CONTROL (mean \pm S.E.M.) & BMP7v (mean \pm S.E.M.) & $\boldsymbol{P}$ \\
\hline \multicolumn{4}{|l|}{2 Weeks } \\
\hline$n$ & 3 & 3 & \\
\hline Cranio-caudal extension $(\mu \mathrm{m})$ & $2160 \pm 183$ & $1000 \pm 144$ & 0.008 \\
\hline Tumor volume $\left(\mu \mathrm{m}^{3}\right)$ & $88 \pm 15 \times 10^{6}$ & $32 \pm 9 \times 10^{6}$ & 0.033 \\
\hline Mitotic index (\%) & $1.57 \pm 0.41$ & $0.930 \pm 0.24$ & NS \\
\hline GFAP-positive cells (\%) & None & None & NA \\
\hline \multicolumn{4}{|l|}{4 Weeks } \\
\hline$n$ & 3 & 3 & \\
\hline Cranio-caudal extension ( $\mu \mathrm{m})$ & $3200 \pm 174$ & $1280 \pm 418$ & 0.013 \\
\hline Tumor volume $\left(\mu \mathrm{m}^{3}\right)$ & $613 \pm 91 \times 10^{6}$ & $247 \pm 63 \times 10^{6}$ & 0.030 \\
\hline Mitotic index (\%) & $2.00 \pm 0.21$ & $1.30 \pm 0.22$ & NS \\
\hline GFAP-positive cells (\%) & $1.30 \pm 0.21$ & $2.00 \pm 0.25$ & NS \\
\hline \multicolumn{4}{|l|}{8 Weeks } \\
\hline$n$ & 4 & 4 & \\
\hline Cranio-caudal extension $(\mu \mathrm{m})$ & $3690 \pm 133$ & $2340 \pm 304$ & 0.007 \\
\hline Tumor volume $\left(\mu \mathrm{m}^{3}\right)$ & $4580 \pm 428 \times 10^{6}$ & $2080 \pm 226 \times 10^{6}$ & 0.002 \\
\hline Mitotic index (\%) & $3.57 \pm 0.23$ & $2.70 \pm 0.19$ & 0.027 \\
\hline Nestin-positive cells (\%) & $81.0 \pm 1.47$ & $63.8 \pm 3.53$ & 0.008 \\
\hline GFAP-positive cells (\%) & $2.15 \pm 0.16$ & $3.62 \pm 0.15$ & $<0.001$ \\
\hline$\beta$ III Tubulin-positive cells (\%) & $3.12 \pm 0.47$ & $7.67 \pm 1.26$ & 0.001 \\
\hline Ki67-positive cells (\%) & $20.8 \pm 0.76$ & $17.2 \pm 0.35$ & 0.041 \\
\hline CD31-positive capillaries (per HPF) & $2.46 \pm 0.22$ & $1.40 \pm 0.37$ & 0.026 \\
\hline CD31-positive vascular glomeruli (per section) & $7.25 \pm 0.59$ & $4.25 \pm 0.36$ & 0.002 \\
\hline
\end{tabular}

Abbreviations: GFAP, glial fibrillary acidic protein; NA, not applicable; NS, not significant; HPF, high power field. 
with controls, suggesting that BMP7v treatment enhanced terminal differentiation (Supplementary Figure S7).

\section{Discussion}

GBM, the most common adult brain tumor, is ultimately unresponsive to virtually all current forms of treatment. It is increasingly apparent that GBM is likely maintained by GSLCs, a minor component of bulk tumor tissue, whereas the majority of the tumor consists of differentiated progenitors with limited clonogenicity. ${ }^{4}$ GSLCs therefore represent a subpopulation of cancer cells with the ability to promote tumor angiogenesis, invasion, therapeutic resistance, and local recurrence and dissemination after treatment, making them a critical target for novel therapy. ${ }^{6}$ According to the CSC theory, it is likely that the GSLCs isolated from patients contain a combination of CSCs, cancer progenitors, and early precursors. The 11 GSLC lines analyzed in this report demonstrated heterogeneity in terms of proliferative potential and basal expression of stem cell markers (Sox2, Nestin, Olig2, and Nanog), along with astrocyte (GFAP) and neuronal ( $\beta$ III-tubulin) markers typical of a differentiated state. BMP7v reduced proliferation in all GSLC lines analyzed without an effect on cell viability. In contrast, BMP7v did not alter proliferation of U-87-MG cells or 10 additional differentiated tumor cell-culture lines representing a range of histologies, indicating that BMP7v specifically targets the GSLC population.

Elevated levels of the stem cell markers Nestin, Sox2, and Olig2 correlate with increased glioma malignancy and decreased overall patient survival. ${ }^{28-30}$ In addition, silencing of Sox2 in freshly isolated GSLCs halted proliferation and inhibited tumorigenicity in immunodeficient mice, ${ }^{31}$ whereas Olig2 is required for GSLC tumor initiation and growth in vivo. ${ }^{32}$ Besides decreasing GSLC proliferation, BMP7v reduced protein expression of the stem cell markers Nestin, Sox2, Olig2, and Nanog in all GSLC lines in vitro, and markedly increased protein expression of differentiation markers such as GFAP, an intermediate filament protein considered a marker of mature and reactive astrocytes, and the neuronal marker $\beta \mathrm{III}$ tubulin in GSLCs in vitro and in vivo. Consequently, following intracerebral GSLC injection, BMP7v reduced expression of key tumorigenic targets that correlated with decreased tumor growth and invasion. BMP7v also reduced the growth and increased the differentiation of GSLCs following subcutaneous injection, indicating that BMP7v treatment is also effective on an established tumor.

A single treatment with BMP7v in an orthotopic intracerebral GSLC xenograft model elicited a marked reduction in tumor growth, invasion, angiogenesis, and prolonged survival. This suggests that a single BMP7v treatment in GBM patients may be sufficient to induce differentiation of GSLCs and reduce their tumorigenicity. Similar to our results with recombinant BMP7v, neural precursor cells have been shown to release wild-type BMP7 that down-regulates Olig2 expression in GSLCs and attenuates GSLC tumorigenicity. ${ }^{33}$ In addition to BMP7, BMP4 also inhibits proliferation and tumorigenicity of colorectal CSCs and GSLCs, although inducing differentiation ${ }^{34,35}$; however, to date, BMP4 has not been shown to have antiangiogenic activity. These results indicate a potential role for targeting BMP signaling for GBM therapy.

The dependence of tumor growth on angiogenesis is a powerful rationale for antiangiogenic approaches for cancer therapy. Targeting blood vessels in brain tumors has been particularly attractive, given the characteristic high degree of endothelial proliferation, vascular permeability, and proangiogenic growth factor expression. ${ }^{36}$ In an in vitro system, BMP7v inhibited endothelial cord formation induced by GSLCs while in vivo, BMP7v-treated GSLC tumors displayed a reduction in CD31 expressing capillaries and vascular glomeruli. Our results demonstrate that BMP7v not only reduces angiogenesis but also depletes the GSLC pool by inducing differentiation, dramatically inhibiting the tumorigenicity of GSLCs in both a subcutaneous and intracerebral GBM model. BMP7v represents a potentially powerful GSLC treatment approach that may prevent the growth and recurrence of GBM.

\section{Materials and Methods}

Cell culture and BMP7 treatment. U-87-MG, SK-OV-3, 786-0, A-375, A-549, A-2780, MDA-MB-231, PC-3, HCT-116, and H-1975 cells were grown according to American Type Culture Collection (ATCC, Manassas, VA, USA) guidelines. For cell proliferation experiments, U-87-MG cells were grown in Dulbelcco's modified Eagle's medium (DMEM) supplemented with $10 \%$ fetal bovine serum (FBS; Invitrogen, Carlsbad, CA, USA), 1\% FBS, or in serum-free media. LXFA-629 non-small-cell lung adenocarcinoma cells (Oncotest, Freiburg, Germany) were maintained in RPMI 1640 medium (Invitrogen) supplemented with $10 \%$ heat-inactivated FBS (Invitrogen) and $1 \%$ glutamine (Invitrogen). GSLCs were isolated from primary tumors, mechanically dissociated, and grown as neurospheres in the absence of FBS and presence of EGF and bFGF as previously described. ${ }^{3,14}$ GSLCs were grown for up to 15 passages, and U-87-MG cells were grown for 7 days to form semi-adherent neurospheres in Neural Progenitor Maintenance Media Bullet Kit supplemented with EGF, bFGF, neural survival factor-1, and gentamicin/amphotericin (Lonza, Basel, Switzerland). All cells were grown and treated in tissue culture-treated flasks in a humidified atmosphere at $37^{\circ} \mathrm{C}$ and $5 \% \mathrm{CO}_{2}$.

The major limitations facing researchers and subsequent pharmaceutical development of BMP7 are the challenges faced with its poor expression from mammalian cells and its suboptimal solubility at neutral $\mathrm{pH}^{37}$ In a manner similar to that described previously, ${ }^{37}$ we introduced mutations into the $\mathrm{N}$ terminus of the BMP7 prodomain to enhance prodomain and mature domain cleavage. In addition, a random mutagenesis approach was used that introduced point mutations onto the surface of the mature domain. Individual beneficial point mutations were combined, five in total, to create a molecule that retained the same signaling properties of wildtype BMP7 but had greater expression and enhanced biophysical properties such as solubility and stability (data not shown). BMP7v material can be made available to researchers upon request to the Lilly authors.

Constructs for wild-type BMP7 and BMP7v were produced and stably transfected into GS-CHO cells grown in serum-free medium. The harvest was applied to a $5.0 \times 20 \mathrm{~cm}$ chelating sepharose column loaded with zinc (equilibrated to PBS, pH 7.4). After sample application, the resin was washed with two column volumes of 0.5 $\mathrm{M} \mathrm{NaCl}$ in PBS, and the target proteins were eluted with an imidazole gradient in PBS at pH 6.5. The fractions with highest purity BMP7, measured by reverse-phase high-performance liquid chromatography analysis, were pooled and filtered through a $0.22 \mu$ membrane. The filtrate was concentrated by tangential flow filtration on a 10000 molecular weight cutoff membrane. The concentrates were applied to $5 \mathrm{~cm}$ by $57 \mathrm{~cm}$ Superdex 200 size exclusion columns, and elution fractions corresponding to pro-forms of wild-type and variant were pooled, sterile filtered, and confirmed for BMP7 activity.

For in vitro BMP7v treatment $(100 \mathrm{ng} / \mathrm{ml})$, neurospheres were dissociated into single cells using TrypLE express (Invitrogen), and 20000 cells were plated in 6-well tissue culture plates, $1 \times 10^{6}$ cells in T75 cell culture flasks for morphology and western blot, and 2000 cells in poly-D-lysine-coated 96 -well tissue culture plates for high-content image analysis or on laminin-coated 96-well tissue culture plates for morphology (both from Becton, Dickinson and Company, Franklin Lakes, NJ, USA). 
Cells were incubated for $24 \mathrm{~h}$ before treatment, and media containing PBS or BMP7v were replaced every 7 days as needed. For CellTiter-Glo Luminescent Cell Viability Assay (Promega, Madison, WI, USA), dissociated cells were plated at 1000 cells per well in poly-D-lysine-coated 96-well tissue culture plates (Becton, Dickinson and Company), and fluorescence was analyzed after 7 days of treatment according to the manufacturer's recommendations using a Wallac Victor2 Multilabel Counter (Perkin Elmer, Waltham, MA, USA).

Immunofluorescence. U-87-MG and GSLCs were directly fixed in the plate for $20 \mathrm{~min}$ at $25^{\circ} \mathrm{C}$ with a final concentration of $3.7 \%$ formaldehyde (SigmaAldrich, St. Louis, MO, USA). Cells were washed once with PBS, permeabilized with $0.1 \%$ Triton $\mathrm{X}-100$ for $15 \mathrm{~min}$, then washed again. Cells were blocked with $1 \%$ bovine serum albumin (BSA; Invitrogen) for $1 \mathrm{~h}$. Primary antibodies against phosphorylated histone $\mathrm{H} 3$ (Ser10) and $\beta$ III-tubulin (both from Millipore, Billerica, MA, USA); and GFAP (Cell Signaling Technology, Danvers, MA, USA) were diluted in $1 \%$ BSA to a final concentration of $5 \mu \mathrm{g} / \mathrm{ml}$ and incubated for $1 \mathrm{~h}$. Cells were washed three times with PBS and incubated for $1 \mathrm{~h}$ with $5 \mu \mathrm{g} / \mathrm{ml}$ goat $\alpha$ mouse-Alexa-488, and/or $5 \mu \mathrm{g} / \mathrm{ml}$ goat $\alpha$-rabbit-Alexa- 647 , and $200 \mathrm{ng} / \mathrm{ml}$ Hoechst 33342 (Molecular Probes, Carlsbad, CA, USA) in 1\% BSA. Cells were washed three times with PBS, then imaged using a Cellomics ArrayScan VTI at a magnification of 10X (Thermo Fisher Scientific, Waltham, MA, USA) and analyzed with the Target Activation BioApplication. A minimum of 1500 individual cellular images were captured, and nuclear area and intensity from each channel were measured. Data were log2-transformed and visualized using unsupervised $\mathrm{K}$-means clustering as previously reported ${ }^{38}$ All populations were compared with PBS-treated control populations. Subpopulations were derived from the entire population of each cell type and intensities based on the number of S.D. away from the mean of the control population.

Western blot analysis. Whole-cell protein extracts were isolated by cell lysis with $1 \%$ SDS and brief sonication, and protein concentration was quantified using the Bradford method. Protein of $25 \mu \mathrm{g}$ was subjected to electrophoresis on $4-20 \%$ pre-cast Tris-glycine gradient gels (Invitrogen), transferred to nitrocellulose (Invitrogen), blocked with $5 \%$ blotting grade blocker (Biorad, Hercules, CA, USA) in Tris-buffered saline containing $0.1 \%$ tween (TBST), probed with primary antiserum, washed with TBST, and incubated with horseradish peroxidise-labeled secondary antibody. Membranes were washed with TBST, and signal was detected by ECL (Thermo Fisher Scientific, Fremont, CA, USA). Antiserum directed against Ki67 (Thermo Fisher Scientific); PARP, cleaved PARP (Asp214), GFAP, Nanog, phosphorylated Smad1 (Ser463/465)/Smad5 (Ser463/465)/Smad8 (Ser426/428), and Sox2 (all from Cell Signaling Technology); phosphorylated histone $\mathrm{H} 3$ (Ser10) and Blll-tubulin (both from Millipore); Nestin and histone H3 (both from Abcam); Olig2 (SDIX, Newark, DE, USA); and $\beta$-actin (Sigma-Aldrich) were diluted with $5 \%$ blotting grade blocker (Biorad) in TBST.

In vitro cord formation assay. Cells were plated and treatments were performed in MCDB-131 medium containing $1 \%$ glutamine, $10 \mu \mathrm{g} / \mathrm{ml}$ human recombinant insulin (all from Invitrogen), $10 \mu \mathrm{g} / \mathrm{ml}$ CellPrime r-transferrin AF (Millipore), $30 \mu \mathrm{g} / \mathrm{ml} \mathrm{L}$-ascorbic acid 2-phosphate and $1 \mu \mathrm{M}$ dexamethasone (both from Sigma-Aldrich). ADSCs (Zen-Bio, Research Triangle Park, NC, USA) were plated at 75000 cells per well into 96-well HTS Trans-well receiver plates (Corning, Lowell, MA, USA), and GSLCs were plated at 25000 cells per well as single cells in 96-well HTS Trans-well plates (Corning) for $24 \mathrm{~h}$, then ADSC media was removed and 6000 human ECFCs (Lonza) per well were over seeded. PBS or BMP7v $(100 \mathrm{ng} / \mathrm{ml})$ were added $4 \mathrm{~h}$ following ECFC plating and incubated for $96 \mathrm{~h}$. Cells were directly fixed for $10 \mathrm{~min}$ with $3.7 \%$ formaldehyde (Sigma-Aldrich) followed by ice-cold $70 \%$ ethanol for $20 \mathrm{~min}$ at $25^{\circ} \mathrm{C}$. Cells were rinsed once with PBS, blocked for $30 \mathrm{~min}$ with $1 \% \mathrm{BSA}$, and immunostained for $1 \mathrm{~h}$ with antiserum directed against CD31 (R\&D Systems, Minneapolis, MN, USA) diluted to $1 \mu \mathrm{g} / \mathrm{ml}$ in $1 \%$ BSA. Cells were washed three times with PBS and incubated for $1 \mathrm{~h}$ with $5 \mu \mathrm{g} / \mathrm{ml}$ donkey $\alpha$-sheep-Alexa-488 (Molecular Probes), $\alpha$-Smooth Muscle Actin Cy3 conjugate (1:200, Sigma-Aldrich), and $200 \mathrm{ng} / \mathrm{ml}$ Hoechst 33342 (Molecular Probes) in $1 \%$ BSA, washed with PBS, then imaged using the cord formation algorithm on the Cellomics ArrayScan VTI at a magnification of $5 \mathrm{X}$ (Thermo Fisher Scientific).

Cytokine analysis. GSLCs $\left(2 \times 10^{5}\right)$ were plated in co-culture media (from cord formation protocol above) in 6-well tissue culture dishes. PBS and BMP7V $(100 \mathrm{ng} / \mathrm{ml})$ were added $24 \mathrm{~h}$ after GSLC plating. Following $72 \mathrm{~h}$ incubation, media was collected and total cell numbers were counted. Cell debris was removed from conditioned media by centrifugation, and samples were analyzed with Quantikine Colorimetric Sandwich ELISAs (R\&D Systems) according to the manufacturer's recommendations.

Subcutaneous grafting of GSLCs. Experiments involving animals were approved by the Ethical Committee of the Catholic University School of Medicine, Rome. Nude athymic mice (4-6 weeks of age; HDS-athymic nude mice, Charles Rives, Milan, Italy) were implanted subcutaneously with $5 \times 10^{5}$ GSLCs., ${ }^{9,14}$ For grafting, cells were resuspended in $0.1 \mathrm{ml}$ of cold PBS and the suspension was mixed with an equal volume of cold Matrigel (BD Bioscience, Bedford, MA, USA). Mice were kept under pathogen-free conditions in positive-pressure cabinets (Tecniplast Gazzada, Varese, Italy) and observed daily for the visual appearance of tumors at injection sites. Tumor diameter was measured using calipers and calculated as the mean value between the shortest and the longest diameters. At 16 weeks after grafting, treatment with BMP7v was started. BMP7v (10 ng in $100 \mu$ l of saline) was injected subcutaneously once daily for 2 weeks ( 5 days per week; total 10 injections). Mice were maintained up to 14 days without any further treatment, except for measurement of tumor mass, then killed with an overdose of barbiturate. Controls included tumors subcutaneously injected with an equal volume of saline.

Intracranial implantation of GSLCs in immunocompromised mice. NOD-SCID mice (4-6 weeks old; Charles River, Italy) were implanted intracranially with $2 \times 10^{5}$ GFP-expressing GSLCs resuspended in $5 \mu \mathrm{l}$ of serumfree DMEM containing $1 \mathrm{ng}$ of BMP7v. Control mice were injected with an equal GSLC suspension without BMP7v. For grafting, the mice were anesthetized with intraperitoneal injection of diazepam $(2 \mathrm{mg} / 100 \mathrm{~g})$ followed by intramuscular injection of ketamine $(4 \mathrm{mg} / 100 \mathrm{~g})$. Animal skulls were immobilized in a stereotactic head frame and a burr hole was made $2 \mathrm{~mm}$ right of the midline and $1 \mathrm{~mm}$ anterior to the coronal suture, and cells were slowly injected using the tip of a 10- $\mu$ l Hamilton microsyringe placed at a depth of $3.5 \mathrm{~mm}$ from the dura. After 2, 4 , and 8 weeks of survival, mice were deeply anesthetized and transcardially perfused with $0.1 \mathrm{M}$ PBS $(\mathrm{pH} 7.4)$ then treated with $4 \%$ paraformaldehyde in $0.1 \mathrm{M}$ PBS. The brain was removed, stored in $30 \%$ sucrose buffer overnight at $4{ }^{\circ} \mathrm{C}$, and serially cryotomed at $20 \mu \mathrm{m}$ on the coronal plane. Sections were collected in distilled water, mounted on slides, and cover-slipped with Eukitt. Images were obtained with a Laser Scanning Confocal Microscope (IX81, Olympus Inc., Melville, NY, USA). In order to obtain survival curves, a subset of animals, which included both BMP7v-treated and -untreated mice, were allowed to survive until the appearance of a lethargic state; whereupon the mice were killed and their brains were analyzed by conventional histology.

Histological and immunohistochemical analysis of brain tumor xenografts. The proliferative potential of the tumor xenografts was assessed by determining the Ml of the GFP-expressing cells on sections counterstained with DAPI and quantified as the percentage of cells in mitosis relative to the total number of nuclei in 20 non-superimposing high-power fields. In each tumor specimen, approximately 1500 tumor cells were counted. The cranio-caudal extension of the brain area invaded by GFP-expressing tumor cells was assessed on serial coronal sections. The volume of the brain invaded by the tumor was determined according to the equation: $V=\left(a^{2} \times b\right) / 2$, where $a$ is the mean transverse diameter of the tumor calculated on coronal sections through the tumor epicenter and $b$ is the cranio-caudal extension of the tumor. ${ }^{39}$ Immunofluorescence was performed as previously described ${ }^{40}$ utilizing antiserum directed against Nestin and $\beta I I I$ Tubulin (both from Millipore), GFAP, Ki67 and FVIII (von Willebrand Factor) (all from Dako, Glostrup, Denmark), GFP (ABGENT, San Diego, CA, USA), CD31, and TIE2 (both from SantaCruz Biotechnology, Santa Cruz, CA, USA). To calculate the percentage of antigen-expressing tumor cells, at least 1500 cells were counted across 10 different fields. The density of tumor vessels was assessed by counting the number of CD31-positive capillaries in 10 non-superimposing high power fields across the grafted striatum in specimens with 8-week survival. The vascular glomeruli, which are typically found at the periphery or even beyond the actual confines of the brain xenograft, were counted along the tumor perimeter in sections passing through the tumor epicenter. In paraffinized sections $(5-\mu \mathrm{m}$ thick), heat-induced antigen retrieval technique by microwave oven processing ( 2 cycles of $5 \mathrm{~min}, 750 \mathrm{~W}$ ) in citrate buffer was used. The sections were incubated with antibody for $1 \mathrm{~h}$, and immunodetection was performed using the avidin-biotin complex peroxidase method (Dako) with fresh diaminobenzidine 
as a chromagen. Alternate sections were stained with hematoxylin and eosin (H\&E) for morphological analysis.

Statistical analysis. Statistical significance was assessed by a two-tailed Student $t$-test with equal variance compared with the data obtained for PBS controls (in vitro) or control groups (in vivo). The log rank test was used to compare survival between BMP7v-treated and control mice. Statistical significance was assigned to $P$-values $<0.05$.

\section{Conflict of Interest}

Authors affiliated with Eli Lilly and Company have Eli Lilly and Company shares received via $401(\mathrm{k})$ and bonus plans.

Acknowledgements. We thank J Dempsey for help with Flow Cytometry, $M$ Swearingen and M Uhlik for in vitro cord formation assay development. This study was partly supported by Università Cattolica del Sacro Cuore, Fondi d'Ateneo, Linea D1 to RP and LML.

1. Furnari F, Fenton $T$, Bachoo R, Mukasa A, Stommel J, Stegh A et al. Malignant astrocytic glioma: genetics, biology and paths to treatment. Genes Dev 2007; 21: 2683-2710.

2. Butowski N, Chang S.. Glial tumors: the current state of scientific knowledge Clin Neurosurg 2006; 53: 106-113.

3. Eramo A, Ricci-Vitiani L, Zeuner A, Pallini R, Lotti F, Sette G et al. Chemotherapy resistance of glioblastoma stem cells. Cell Death Diff 2006; 13: 1238-1241.

4. Singh S, Clarke I, Terasaki M. Identification of a cancer stem cell in human brain tumors Cancer Res 2003; 63: 5821-5828.

5. Vescovi A, Galli R, Reynolds B. Brain tumour stem cells. Nat Rev 2006; 6: 425-435

6. Huang Z, Cheng L, Guryanova $O$, Wu $Q$, Bao S. Cancer stem cells in glioblastomamolecular signaling and therapeutic targeting. Protein Cell 2010; 1: 638-655.

7. Rich J, Bao S. Chemotherapy and cancer stem cells. Cell Stem Cell 2007; 1: 353-355.

8. Bao S, Wu Q, Sathornsumetee S, Hao Y, Li Z, Hjelmeland A et al. Stem cell-like glioma cells promote tumor angiogenesis through vascular endothlial growth factor. Cancer Res 2006; 66: 7843-7848.

9. Ricci-Vitiani L, Pallini R, Biffoni M, Todaro M, Invernici G, Cenci T et al. Tumour vascularization via endothelial differntiation of glioblastoma stem-like cells. Nature 2010; 468: 824-828.

10. Wang R, Chadalavada K, Wilshire J, Kowalik U, Hovinga K, Geber A et al. Glioblastoma stem-like cells give rise to tumour endothelium. Nature 2010; 468: 829-833.

11. Lee J, Jin Son M, Woolard K, Donin N, Li A, Cheng C-H et al. Epigenetic-mediated dysfunction of the bone morphogenetic protein developmental pathway inhibits differentiation of human glioblastoma tumor initiating cells. Cancer Cell 2008; 13: 69-80.

12. Gross R, Mehler M, Mabie P, Zang Z, Santschi L, Kessler J. Bone morphogenetic proteins promote astroglial lineage commitment by mammalian subventricular zone progenitor cells. Neuron 1996; 17: 595-606.

13. Anderson G, Darshan D. Small-molecule dissection of BMP signaling. Nature Chemical Biology 2008; 4: 15-16.

14. Pallini R, Ricci-Vitiani L, Banna G, Signore M, Lombardi D, Todaro M et al. Cancer stem cell analysis and clinical outcome in patients with glioblastoma multiforme. Clin Cancer Res 2008; 14: 8205-7212.

15. Low J, Dowless M, Shiyanova T, Rowlinson S, Ricci-Vitiani L, De Maria R et al. Knockdown of cancer testis antigens modulates neural stem cell marker expression in glioblastoma tumor stem cells. J Biomol Screen 2010; 15: 830-839

16. Annovazzi L, Mellai M. Caldera V, Valente G, Schiffer D. SOX2 expression and amplification in gliomas and glioma cell lines. Cancer Genom Proteom 2011; 8: 139-147.

17. Po A, Ferretti E, Miele E, De Smaele E, Paganelli A, Canettieri G et al. Hedgehog controls neural stem cells through p53-independent regulation of Nanog. EMBO J 2010; 29: $2646-2658$.
18. Bao S, Wu Q, Li Z, Sathornsumetee S, Wang H, McLendon R et al. Targeting cancer stem cells through L1CAM suppresses glioma growth. Cancer Res 2008; 68: 6043-6048.

19. Holland E. Progenitor cells and glioma formation. Curr Opin Neurol 2001; 14: 683-688.

20. Duggal N, Hammond R. Nestin expression in ganglioglioma. Exp Neurol 2002; 174: 89-95.

21. Lamszus K, Gunther H. Glioma stem cells as a target for treatment. Target Oncol 2010; 5 211-215.

22. Ricci-Vitiani L, Pallini R, Larocca L, Lombadi D, Signore M, Pierconti F et al. Mesenchymal differentiation of glioblastoma stem cells. Cell Death Diff 2008; 15 : 1491-1498.

23. Low J, Huang S, Blosser W, Dowless M, Burch J, Neubauer B et al. High content imaging characterization of cell cycle therapeutics through in vitro and in vivo subpopulation analysis. Mol Cancer Ther 2008; 7: 2455-2463.

24. Galli R, Binda E, Orfanelli U, Cipelletti B, Gritti A, De Vitis $S$ et al. Isolation and characterization of tumorigenic, stem-like neural precursors from human glioblastoma. Cancer Res 2004; 64: 7011-7021.

25. Piccirillo S, Binda E, Fiocco R, Vescovi A, Shah K. Brain cancer stem cells. J Mol Med 2009; 87: 1087-1095.

26. Li Z, Bao S, Wu Q, Wang H, Eyler C, Sathornsumetee $S$ et al. Hypoxia inducible factors regulate tumorigenic capacity of glioma stem cells. Cancer Cell 2009; 15 : 501-513.

27. Hogan B. Bone morphogenetic proteins in development. Curr Opin Genet Dev 1996; 6 : 432-438.

28. Cavallaro M, Mariani J, Lancini C, Latorre E, Caccia R, Gullo F et al. Impaired generation of mature neurons by neural stem cells from hypomorphic Sox2 mutants. Development 2008; 135: 541-557.

29. Ferri A, Cavallaro M, Braida D, Cristofano A, Canta A, Vezzani A et al. Sox2 deficiency causes neurdegeneration and impaired neurogenesis in the adult mouse brain. Development 2004; 131: 3805-3819.

30. Strojnik T, Rosland G, Sakariassen P, Kavalar R, Lah T. Neural stem cell markers, nestin and musashi proteins, in the progression of human glioma: correlation of nestin with prognosis of patient survival. Surg Neurol 2007; 68: 133-143.

31. Gangemi R, Griffero F, Marubbi D, Perera M, Capra M, Malatesta P et al. SOX2 silencing in glioblastoma tumor-initiating cells causes stop of proliferation and loss of tumorigenicity. Stem Cells 2009; 27: 40-48.

32. Ligon K, Huilard E, Mehta S, Kesari S, Liu H, Alberta J et al. Olig2-regulated lineagerestricted pathway controls replication competence in neural stem cells and malignant glioma. Neuron 2007; 53: 503-517.

33. Chirasani S, Sternjak A, Wend P, Momma S, Campos B, Herrmann I et al. Bone morphogenetic protein-7 release from endogenous neural precursor cells suppresses the tumourigenicity of stem-like glioblastoma cells. Brain 2010; 133: 1961-1972.

34. Lombardo $\mathrm{Y}$, Scopelliti A, Cammareri $\mathrm{P}$, Todaro M, lovino $\mathrm{F}$, Ricci-Vitiani $\mathrm{L}$ et al. Bone morphogenetic protein 4 induces differentiation of colorectal cancer stem cells and increases their response to chemotherapy in mice. Gastroenterology 2011; 140: 297-309.

35. Piccirillo S, Reynolds B, Zanetti N, Lamorte G, Binda E, Broggi G et al. Bone morphogenetic proteins inhibit the tumorigenic potential of human brain tumour-initiating cells. Nature 2006; 444: 761-765.

36. Jain R, di Tomaso E, Duda D, Loeffler J, Sorensen A, Batchelor T. Angiogenesis in brain tumours. Nature 2007; 8: 610-622.

37. Swencki-Underwood B, Mills J, Vennarini J, Boakye K, Luo J, Pomerantz S. Expression and characterization of a human BMP-7 variant with improved biochemical properties. Protein Expr Purif 2008; 57: 312-319.

38. Low J, Shuguang H, Dowless M, Blosser W, Vincent T, Davis S et al. High-content imaging analysis of the knockdown effects of validated siRNAs and antisense oligonucleotides J Biomol Screen 2007; 12: 776-788.

39. Pallini R, Sorrentino A, Pierconti F, Maggiano N, Faggi R, Montano M et al. Telomerase inhibition by stable RNA interference impairs tumor growth and angiogenesis in glioblastoma xenografts. Int J Cancer 2006; 118: 2158-2167.

40. Mollinari C, Ricci-Vitiani L, Pieri M, Lucantoni C, Rinaldi A, Racaniello $M$ et al. Downregulation of thymosin beta 4 in neural progenitor grafts promotes spinal cord regeneration. J Cell Sci 2009; 122: 4195-4207. 